\title{
How does it really feel to act together? : Shared emotions and the phenomenology of we-agency
}

\section{Salmela, Mikko Erkki Matias}

2017-07

Salmela , M E M \& Nagatsu , M 2017 , ' How does it really feel to act together? Shared emotions and the phenomenology of we-agency ', Phenomenology and the Cognitive pÿSciences , vol. 16 , no. 3 , pp. 449470 . https://doi.org/10.1007/s11097-016-9465-z

http://hdl.handle.net/10138/233125

https://doi.org/10.1007/s11097-016-9465-z

publishedVersion

Downloaded from Helda, University of Helsinki institutional repository.

This is an electronic reprint of the original article.

This reprint may differ from the original in pagination and typographic detail.

Please cite the original version. 


\title{
How does it really feel to act together? Shared emotions and the phenomenology of we-agency
}

\author{
Mikko Salmela $^{1} \cdot$ Michiru Nagatsu $^{1}$
}

Published online: 31 March 2016

(C) Springer Science+Business Media Dordrecht 2016

\begin{abstract}
Research on the phenomenology of agency for joint action has so far focused on the sense of agency and control in joint action, leaving aside questions on how it feels to act together. This paper tries to fill this gap in a way consistent with the existing theories of joint action and shared emotion. We first reconstruct Pacherie's (Phenomenology and the Cognitive Sciences, 13, 25-46, 2014) account on the phenomenology of agency for joint action, pointing out its two problems, namely (1) the necessary trade-off between the sense of self- and weagency; and (2) the lack of affective phenomenology of joint action in general. After elaborating on these criticisms based on our theory of shared emotion, we substantiate the second criticism by discussing different mechanisms of shared affect-feelings and emotions - that are present in typical joint actions. We show that our account improves on Pacherie's, first by introducing our agentive model of we-agency to overcome her unnecessary dichotomy between a sense of self- and we-agency, and then by suggesting that the mechanisms of shared affect enhance not only the predictability of other agents' actions as Pacherie highlights, but also an agentive sense of we-agency that emerges from shared emotions experienced in the course and consequence of joint action.
\end{abstract}

Keywords Phenomenology $\cdot$ Joint action $\cdot$ we-agency $\cdot$ Shared emotions

$\underline{\text { Mikko Salmela and Michiru Nagatsu contributed equally to this work. }}$

Michiru Nagatsu

michiru.nagatsu@helsinki.fi

Mikko Salmela

mikko.salmela@helsinki.fi

1 Academy of Finland Centre of Excellence in the Philosophy of Social Sciences (TINT), Department of Political and Economic Studies, Social and Moral Philosophy, University of Helsinki, Helsinki, Finland 


\section{Introduction}

Phenomenology of joint action is a new interdisciplinary field in the research of joint action. It has two roots: philosophical studies on the role of shared intentions in rationally guiding and coordinating joint action; and empirical research on the cognitive, perceptual, motor, and behavioral processes that enable individuals to coordinate their actions, often without conscious awareness. Drawing on research on the phenomenology of individual action and experiences of individual agency, philosophers Elisabeth Pacherie (2012, 2014) and Deborah Tollefsen (2014) have proposed models that purport to explain the phenomenology of joint action by integrating these philosophical and empirical approaches. Surprisingly, however, both Pacherie and Tollefsen largely neglect the affective phenomenology of joint action, although one would expect otherwise from the title of one of Pacherie's recent articles, "How does it feel to act together?" The goal of this article, whose title slightly modifies that of Pacherie's, is to fill this affective gap in the phenomenology of joint action.

We believe that this neglect is due to the close modeling of the phenomenology of joint action on that of individual action, in which interpersonal affective processes do not play a specific role. Researchers instead focus on mechanisms of action specification and control that make joint action more complex than individual action, and on the implications of these demands for the sense of agency and control in joint action. In contrast to this cognitive approach, ours highlights the central roles affective rewards (Godman 2013) play in creating the sense of we-agency, and the underlying motivational structures of joint action (Godman et al. 2014). This allows us to develop an account of the sense of agency for joint action, ${ }^{1}$ in which Pacherie's (2014) two senses of agency for joint action, namely, "a sense of agency for joint outcomes" and " a sense of we-agency" are integrated.

The paper proceeds as follows: we first reconstruct Pacherie's (2014) account on the phenomenology of agency for joint action (Section 2). Another notable contribution is Tollefsen (2014), but we focus on Pacherie as it is more elaborate. ${ }^{2}$ Then we formulate two problems concerning Pacherie's account, namely (1) that her view on the sense of we-agency as a fusion of individual and agency for joint action implies a tradeoff between the sense of self- and we-agency, which on our account is not necessary; and (2) that her account is silent on the affective phenomenology of joint action in general, which is a necessary and central building block of the account of a sense of we-agency we develop (Section 3). Regarding the first criticism, we elucidate the ambiguous

\footnotetext{
${ }^{1}$ Throughout the paper we use the term "agency for joint action" to refer to the general idea of agency which is distinct from individual agency. One may well use "collective agency", "joint agency" or "shared agency" instead, but the important point is that the term is not dependent on any specific theory of non-individual agency.

${ }^{2}$ Tollefsen's (2014) brief account of the sense of joint control in joint action is similar to Pacherie's sense of agency for joint outcomes in that it builds on a perceived match between the predicted and actual effects of agency for joint action. The difference is that Tollefsen relates the sense of joint control functionally to controlling and monitoring joint action, whereas for Pacherie, the phenomenology of we-agency is interesting in its own right.
} 
notion of "shared emotion," drawing on our theory of shared emotion that do not presuppose such dichotomy (Section 4). We substantiate the second criticism by discussing different mechanisms of shared affect-feelings and emotions ${ }^{3}$ - that are present in typical joint actions (Section 5). Finally, in Section 6, we show how our account improves on Pacherie's (2014). Specifically, we propose that these mechanisms of shared affect operate in the same conditions that Pacherie proposes for a sense of agency for joint outcomes. We suggest that these mechanisms enhance not only the predictability of other agents' actions as Pacherie highlights, but also an agentive sense of weagency that emerges centrally from shared emotions experienced in the course and consequence of joint action. Our account of the affective phenomenology of we-agency aims to overcome Pacherie's dichotomy between a sense of selfand we-agency, and to complement her account by identifying an important set of affective mechanisms that enhance the sense of agency for joint outcomes. Section 7 briefly concludes the discussion.

\section{Pacherie on the phenomenology of joint action}

Is the sense of agency for joint action distinct from that of individual agency? In her recent article "How does it feel to act together?" (2014), Pacherie explores two ways in which the former differs from the latter. The first way concerns the extent to which a sense and strength of agency for joint action differs from a sense of agency for individual action. Pacherie calls this "a sense of agency for a joint outcome." (p. 26), which is an outcome-related aspect. The second question is about the emergence of a specific sense of agency for joint action, which Pacherie calls "a sense of we-agency" in joint action, which is an agent-related aspect. ${ }^{4}$ How are these two senses of agency for joint action related? In this section, we reconstruct Pacherie's (2014) account, before highlighting its two problems in Section 3.

\footnotetext{
${ }^{3}$ Feelings and emotions are types of "affect" that we, following a wide interdisciplinary consensus in philosophy, psychology, and sociology, use as an umbrella term for phenomenal states with certain valence and intensity. Emotions are felt evaluative responses to specific objects and events and they motivate the subject to act in accordance with evaluative content of the emotion; to fight or flee in danger, to retaliate or retribute when offended, to hide in shame, and so on. Feelings can be part of emotion, and they can be experienced as bodily sensations or intentional feelings directed at the particular object of emotion or as both kinds of feelings at the same time. However, not all feelings such as rapport or alienation are part of emotions. Thus when we speak about "shared affects", we refer to shared emotions or shared feelings or both. The notion of affect has a different meaning in the so called "affect theory" that is prevalent in cultural, media, and gender studies (see e.g. Gregg and Seigworth 2010).

${ }^{4}$ A possible philosophical worry about Pacherie's - as well as our - project is that it is indeterminate until it is clarified whether the concept of "we" in "we-agency" refers to a distributed or a non-distributed "we" (see e.g. Bratman 2014). An example of the former could be a group of students from different schools celebrating their graduation on the same day, whereas a group of team members celebrating the victory of their team could exemplify the latter kind of "we". Pacherie does not raise this question in her discussion for good reasons, we think. First of all, a theoretically pre-defined "we" may not be salient in the phenomenology of we-agency that purposefully avoids theory-laden accounts of experience. Second, a sharp dichotomy between a distributed and non-distributed "we" may be false in paradigm experiences of we-agency as these may combine a robust sense of self-agency with that of we-agency, as we will argue in what follows.
} 


\subsection{The sense of agency for a joint outcome}

Pacherie suggests that "a sense of agency for a joint outcome" emerges from a match between the predicted and actual consequences of the combined individual actions in joint action. For instance, if you and I intend to prepare hollandaise sauce together by you stirring the sauce and me pouring cream into it, our joint intention specifies the predicted course and consequences of our action, with which the actual consequences match to a greater or lesser extent. Making predictions about joint outcomes is more difficult than making predictions about individual action's outcomes for the obvious reason that other agents' actions remain beyond one's control. Predicting joint outcomes is hard also because the task is more complicated:

Agents must not just predict the consequences of their own actions at all three [cognitive, perceptual, and sensorimotor] levels of action specification (selfpredictions), they must also do the same for the actions of their co-agents (other-predictions), and finally integrate both self- and other-predictions to build predictions about the joint consequences of their combined actions (joint predictions). (Pacherie 2014, 33-34)

As a result,

The strength of the sense of agency for the joint outcome will depend on how accurately one is able to make joint predictions, which in turn depends on the extent and accuracy of self- and other predictions and on the manner of their integration. (ibid.)

Pacherie suggests that such factors as the structure of the joint action, its scale, the degree of specialization of agents' roles, and the longevity of the collective affect the sense of agency for joint action by affecting the availability of relevant information for making accurate joint predictions.

Specifically, Pacherie $(2014,35)$ argues that "participation in small-scale, egalitarian actions, with little specialization of roles and a stable group of co-agents, is likely to yield a stronger sense of agency than first-time participation in a large-scale, hierarchical joint action with highly differentiated roles". This is because these four factors all enhance other- and joint prediction: first, small-scale joint action in a shared physical environment allows the participants to monitor and anticipate each other's actions and the consequences of those actions. Second, in egalitarian action, all participating agents contribute more or less equally to the planning and execution of a joint action for which they are jointly responsible. As the agents participate equally to the decision of the joint goal and planning for it, they get knowledge of the other participants' tasks and their contribution to the joint goal. Third, near-identical or interchangeable roles in a joint action allows the participants to have a motor repertoire "to engage in perception-action matching and motor simulation as well as the knowledge needed to form task representations; they would thus be in a position to precisely represent the goals and actions of their co-agents" (Pacherie 2014, 35). Finally, the stability of the association among co-agents forms a long-term collective whose members are used to working together with many opportunities to form shared task representations. In sum, all these four features of a 
group - small-scale, egalitarian actions, unspecialized roles and stability - contribute to the sense of agency for joint outcomes by facilitating predictions of the actions of their co-agents and the consequences of those actions.

\subsection{The sense of we-agency}

Pacherie distinguishes "a sense of we-agency" from the "sense of agency for a joint outcome." As we saw in 2.1, the latter concerns outcomes over which the individual can feel agency - if the outcome results from joint action the agency can be felt over the joint outcome. However, this analysis does not fully address the question "Is the sense of agency for joint action distinct from that of individual agency?" Pacherie accordingly introduces the former "sense of we-agency," which she identifies with "a merging of one's agency in the collective agency of the group" (Pacherie 2014, 37). Pacherie's basic strategy to elucidate the distinctiveness of this sense of we-agency is to focus on the self-other discrimination:

What form agentive identity takes depends on the extent to which the conditions needed for self-other discrimination obtain. These conditions themselves can be roughly distinguished into, on the one hand, structural conditions, i.e., factors relating to the structural properties of the joint action, such as its more or less pronounced hierarchical organization and division of labor among agents, and, on the other hand, motivational conditions, the latter encompassing both the reasons that motivated the agent to engage in a given joint action in the first place and the motivational effects of the action itself (Pacherie 2014, 37).

Pacherie suggests that "the more commensurate the respective contributions of the co-agents and the more symmetrical the coordination relations among them are (or are perceived to be), the more likely it is that the sense of agency they will experience will involve a shift towards a sense of we-agency" (ibid., 38). The similarity and synchrony of the co-agent's actions contributes to a sense of we-agency by blurring the boundary between self- and other-agency. Insofar as co-agents contribute equally to their shared goal, as in team sports, the specialization of roles need not prevent their experience of we-agency. Pacherie further claims that an even stronger sense of we-agency emerges in joint actions with nearly identical or interchangeable roles such as military drill or communal dancing that allow for a merging of the individual agency to a agency for joint action. These examples also highlight the contribution of shared social identity to the experience of we-agency. Shared social identity can be strengthened by dress codes, hair styles and other visible marks of similarity, as in the military or in team sports.

Relating to the second, motivational conditions of a sense of we-agency, Pacherie observes an important point that "the very motivations that lead an agent to engage in joint action may influence the way agency will be experienced" (p. 40). But she does not develop this further, simply noting that shared social identity is associated with motor synchrony, action co-representation, and cooperativeness. She refers to empirical studies suggesting that group membership modulates nonconscious behavioral mimicry, which, together with motor synchrony, promotes positive relationships, affiliation, prosocial behavior, and cooperation (Chartrand and Bargh 1999; Lakin et al. 2003; van Baaren et al. 2004; Wiltermuth and Heath 2009). Here Pacherie briefly touches on the 
contribution of affects to a phenomenology of we-agency, but the remark remains underdeveloped (we revisit these studies in Section 5).

\section{Two problems of Pacherie's account}

Pacherie's account of the sense of agency for joint action is the most sophisticated one currently available, informed by both the philosophical and empirical literature. However, it suffers from two related problems, which we discuss in turn below.

\subsection{The sense of we-agency as "one-ness"}

The first problem is that it is not clear how the outcome-based sense of agency for joint action and the sense of we-agency are related. On the one hand, the sense of agency for joint outcomes requires the self-other discrimination because her crucial condition for this sense depends on successful self-, other-, and joint-predictions (see also Pacherie 2014, 37). On the other, according to her account the experience of we-agency centrally depends on weakening of the self-other agential distinction. So the two senses of agency for joint action seem to be in tension, one requiring a clear self-other agential distinction while the other demanding its weakening.

A closer look at the structural conditions she identifies for both senses of agency for joint action, however, suggests that there are cases where both senses can be simultaneously strengthened. In particular, joint action with egalitarian and commensurate roles of co-actors facilitates both senses of agency for joint action, by making joint predictions easier (resulting in a stronger sense of agency for joint outcomes) while loosening the self-other boundary (resulting in a stronger sense of we-agency) at the same time. But it is difficult to make sense of a cognitive activity like prediction for joint outcomes when the self-other boundary is blurred. Is it a "we-agent" who is making predictions here? ${ }^{5}$

We therefore propose an alternative conceptualization of the sense of we-agency, which derives from agentively contributing to a shared goal together with others in a cooperative manner. This experience is enacted by sharing a goal and contributing to it jointly with others, and enhanced by successfully achieving it. So it is compatible with Pacherie's "sense of agency for joint outcomes," but it replaces her "sense of weagency" because it doesn't depend on losing or loosening one's agential self in acting as a collective agent.

To see the difference between our agentive notion of a sense of we-agency and that of Pacherie's, recall two examples in which a sense of we-agency can arise, a sport team and a military unit. Pacherie calls the case of the sport team

\footnotetext{
${ }_{5}^{5}$ In interpreting the results of the limited empirical studies on the relation between self-agency and we-agency, Pacherie $(2014,38-39)$ warns against identifying we-agency with pre-reflective cognitive processes that are immune to conscious top-down influence. This cautious note implies that she is thinking of the sense of weagency as something individuals can (at least sometimes) reflectively experience and exert top-down influence on. If this is the case, then the loss of self-other agential boundary seems too strong a condition for her own account of the sense of we-agency.
} 
"mixed" or "intermediate" as opposed to the "pure" case of the military unit because a sense of self-agency in the former remains active whereas it is lost in the latter. Construing the sense of we-agency the team players can have as necessarily a compromised one in this manner, however, creates an unnecessary dichotomy between self-agency and we-agency. On our account, what is necessary is that the individuals are motivated to play their part in achieving a shared goal, and that they have control over their own action that contributes to it. Understood this way, there need not be a trade-off between the sense of selfagency and that of we-agency; that is, increasing one does not necessarily decrease the other.

Of course, we do not deny the experiential distinctiveness and social relevance of the kind of experience Pacherie characterizes as a sense of unity or "one-ness", a loss of boundary between self- and other-agency. It is an empirical question which sense of we-agency is prominent in a given group, and we might speculate that it depends on the kind of joint actions. For example, experiences of boundary loss seem more prevalent in ritualistic joint actions that have no proximate purpose beyond the activity (see Section 5.2 below), whereas experiences of interdependent cooperation emerge in the context of purposive joint action. Both kinds of joint actions clearly have important roles in our social lives.

Nevertheless, we argue that our agentive account of the sense of we-agency has several merits that the "one-ness" account lacks. First, as Pacherie herself points out $(2014,38-39)$, the results of available empirical studies do not support the trade-off between the senses of self- and we-agency. Our account is consistent with this interpretation. Second, our account coheres better with Pacherie's sense of agency for joint outcomes than her own "one-ness" account of we-agency. We show how shared affects can contribute to both Pacherie's sense of agency for joint outcomes and our agentive sense of we-agency without creating any tension between the two (Section 6). Third, our account better accommodates the various forms of affective experience in joint action, which we review in Section 5 below. Finally, our account is more consistent with philosophical analyses of joint action. An awareness of us doing something together conceptually presupposes the awareness of self-agency, two or more individuals experiencing themselves as "us". None of the prominent philosophical theories of we-agency or shared agency requires that individuals are feeling as indiscriminate part of a plural subject that acts when a group acts. ${ }^{6}$ The phenomenologist Dan Zahavi similarly argues that sharing attention or emotions with others has "nothing to do with fusion, nor with a merged unity. Sharing involves a plurality of subjects, but it also involves more than mere summation or aggregation." (Zahavi 2015, 90). We suggest that the same goes with the sense of we-agency: it has more to do with a strong sense of self-other interdependence in action than with losing or loosening the distinction between self and other.

\footnotetext{
${ }^{6}$ Although some theorists attribute intentions to groups in addition to their members, they all admit that groups act only through their members. Gilbert (2014) for example argues that the participants of joint action are jointly committed to constituting, as far as possible, a single subject of action. Yet this only amounts to the parties' being jointly committed to emulating, by virtue of their actions, a single subject of action.
} 


\subsection{How does it really feel like to act together? The affective phenomenology of joint action}

The second problem of Pacherie's (2014) account of the sense of agency in joint action concerns her relative silence on the affective phenomenology of joint action in general, and her understanding of its contribution to a sense of we-agency in particular. ${ }^{7}$ As we noted in Section 2.2, Pacherie rightly observes that "the very motivations that lead an agent to engage in joint action may influence the way agency will be experienced." (p. 40) She also mentions, drawing on empirical studies, several psychological processes through which shared social identity and joint action are mutually reinforced. But she links the affective experience resulting from these processes directly to the sense of weagency based on the loss of self-other distinction, which we criticize above. Now that we proposed an alternative sense of we-agency, we do two things in the remainder of the paper. First, we discuss in further detail the affective phenomenology of joint action, that is, several mechanisms that generate shared affects -feelings and emotions- when individuals pursue and achieve their shared goals together in joint action. We argue that these shared affects render joint action rewarding in their own right and thus motivating for the participants. Second, we show that these affective rewards do not necessarily blur the boundary between self-agency and we-agency. In other words, we try to fill the affective gap in the phenomenology of joint action, in such a way that is consistent with our agentive account of the sense of we-agency.

In order to achieve these goals, we first need to do some preliminary work. We first elucidate the ambiguous notion of "shared emotions" based on our philosophical account of these emotions in Section 4 below. Then we analyze different mechanisms of shared affect that are present in typical joint actions in Section 5. We finally suggest that these mechanisms operate in the same conditions that Pacherie proposes for a sense of agency for joint outcomes, enhancing both the predictability of other agents' actions that Pacherie highlights in her account, and an agentive sense of we-agency that we propose emerges from shared emotions in joint action (Section 6). In this way, our account of the affective phenomenology of we-agency utilizes Pacherie's account of the sense of agency for joint outcomes and replaces Pacherie's unnecessary dichotomy between a sense self-agency and we-agency.

\section{What are shared emotions?}

The notion of "shared emotion" is ambiguous. On the one hand, sharing of emotion refers to a phenomenon in which one person's expressed emotion is perceived by another person. This is the sense that John Michael (2011) and some theorists of empathy (e.g. Rimé 2007) have in mind when they discuss shared emotions. Thus,

\footnotetext{
${ }^{7}$ Her recent paper with John Michael (Michael and Pacherie 2015, p. 107) touches upon this issue in discussing moral sentiments and emotions as an automatic process to reduce uncertainty and achieve cooperation in social dilemma situations. The focus of that paper however is not phenomenological but functional.
} 
Michael gives two necessary but not sufficient conditions for sharing an emotion between two persons, $\mathrm{x}$ and $\mathrm{y}$ :

(a) $\mathrm{x}$ expresses his affective state (verbally or otherwise);

(b) y perceives this expression.

On the other hand, the notion of sharing refers to several individuals experiencing an emotion of the same type and content, such as celebrating the success of their favorite team with other fans, with mutual awareness of their respective emotional state (joy). Most philosophical and empirical accounts of shared and collective emotions have been interested in the latter kind of phenomena, invoking the notion of sharing in this sense. Likewise, we suggest the following formulation: $\mathrm{x}$ and $\mathrm{y}$ share an emotion, or equivalently have a collective emotion if,

(c) $\mathrm{x}$ and $\mathrm{y}$ experience an emotion of the same type with similar:

(i) evaluative content and

(ii) affective experience; and

(d) $\mathrm{x}$ and $\mathrm{y}$ are mutually aware that (c).

Phenomenologically, the evaluative content and affective experience of an emotion are typically intertwined and intentionally directed at the particular object of emotion. While the evaluative content of an emotion is necessarily intentional, the affective experience is only contingently so (see 4.2 below). Both of these main dimensions of emotion can also be elaborated in terms of their degree of collectivity (see Salmela 2012, 2013 for more detailed accounts). ${ }^{8}$

\subsection{Evaluative content}

There is a wide interdisciplinary agreement among emotion researchers that emotions could not exist without underlying concerns, representations with the world-to-mind direction of fit such as desires, goals, norms or values (Roberts 2003). Therefore, when a group of people are said to experience a shared emotion, we must ask what kind of concern they share, and to what extent. In other words, sharing the evaluative content of emotion is a matter of appraising the particular object of emotion similarly with other people on the basis of concerns that can be shared to a varying extent. ${ }^{9}$ We propose that this degree of sharedness of concerns determines the degree of sharedness of emotions.

In the weakest form of collectivity, people have overlapping private concerns. Insofar as people pursue their own survival, security, attachment, health, happiness, and attachment, these are private concerns. Tuomela (2007) calls concerns of this kind plain

\footnotetext{
${ }^{8}$ There are other philosophical theories of shared emotions, most notably those of Gilbert (2002), Schmid (2009), and Huebner (2011). For a discussion and critique of the former two, see Salmela (2012).

${ }^{9}$ The appraisal process need not be collective though it can be in some cases, such as when an emotional appraisal is formed as a result of public discussion (see Halperin 2014). More typically, though, emotional appraisals are so fast and modular that it is impossible to make let alone commit oneself to them collectively (but see Gilbert 2002, 2014).
} 
I-mode concerns. The fact that private concerns are general or even universal among all humans amounts to their being collective in terms of their type but not in terms of their token identity as each person is concerned about getting the relevant goods for him- or herself. In the latter sense, overlapping private concerns are common rather than robustly collective. This implies that concerns of this kind can be in conflict with each other. Concerns can be collective in a stronger sense when individuals are privately committed to some shared token concern [in part because of] believing that the others in the group have the same concern, and also believing this is mutually believed in the group. Thus, for instance, if John as a Liverpool fan is concerned about the future of this prestigious football club, not only does he believe that the other Liverpool fans have the same concern, but also that the other fans believe the same about his and other fans' having the concern in question. The bracketed clause refers to the fact that many of our shared concerns are socially grounded. Tuomela has characterized this type of collectivity as pro-group I-mode or, more recently (Tuomela 2013), weak we-mode collectivity. In contrast to overlapping private concerns, moderately (as well as strongly) collective concerns are non-competitive. Finally, the strongest mode of collectivity in sharing concerns is founded on the group members' collective commitment, either explicit or implicit. Through their collective commitment, the group members adopt the concern as theirs in a strong we-mode sense. Collective commitment provides the group members group reasons to think, want, feel, and act in ways that are in accordance with their shared concern. Moreover, the group members are allowed to revise their commitment to the shared concern only by reasons that are acceptable from the group's point of view.

\subsection{Affective experience}

Shared concerns provide both motivating and justifying reasons for the emergence of shared emotions when individuals perceive that their shared concerns are affected either adversely or favorably. ${ }^{10}$ In addition, shared concerns sometimes give rise to the kind of non-reflective absorption in shared emotional experience in which the evaluative and affective dimensions of emotion become thoroughly intertwined, sometimes taking the form of a phenomenological fusion of feelings into "our" feeling that Schmid (2009) highlights as the core of shared emotions. However, we regard a feeling of phenomenological fusion as neither sufficient nor necessary for sharing emotions: it is not sufficient because it is possible to experience such fusion in the context of otherwise

\footnotetext{
${ }^{10}$ The idea of emotions having reasons may strike one as strange. However, the idea that emotions have both justifying and motivating reasons is widely accepted in contemporary philosophy of emotions and metaethics (e.g. Greenspan 1988 D'Arms and Jacobson 2000 Helm 2008; Brady 2011). Emotions have justifying reasons as they are liable to evaluation in terms of appropriateness like other intentional attitudes. For instance, my fear is appropriate if the object of my fear has properties that render it capable of inflicting significant harm on me. Justifying reasons of shared emotions may refer to collectively accepted attitudes of a group, such as its values, goals, or intentions. The same group attitudes may also serve as motivating reasons of shared emotions. Since emotions are not under voluntary control, there can be no deliberation on reasons to feel in the same way as there is deliberation on reasons to act. However, we can talk about reasons (rather than mere causes) of emotion because human emotions are not reflexes or fixed action patterns but flexible responses to cognitively processed situational meanings.
} 
dissimilar emotions with importantly dissimilar underlying concerns. ${ }^{11}$ The emotion felt as "ours" must also have underlying shared concerns to qualify as strongly collective. Nor is the experience of fusion necessary because a shared emotional experience may take other forms, depending on whether the participants are focusing on the intentional object of emotion or their own bodily states rather than on their "oneness" or togetherness in experiencing the emotion (see Lambie and Marcel 2002).

Instead of highlighting any particular form of shared affective experience as privileged, we want to emphasize a set of mechanisms that is causally responsible for producing shared affectivity that is experienced in different ways. These mechanisms synchronize various aspects of individual emotional responses - physiological changes, facial expressions, action tendencies, and subjective feelings. Causal mechanisms that contribute to the synchronization of emotional responses include attentional deployment (Collins 2004), emotional contagion (Hatfield et al. 1994), facial mimicry (Bourgois and Hess 2008), motor mimicry and imitation (Chartrand and Bargh 1999), and neural mirroring (Decety and Meyer 2008). These mechanisms operate most efficiently when the participants with a shared emotion are physically co-present and jointly attend to the shared object of their emotion as Durkheim (2001) and Collins (2004) propose in their ritualistic sociological theories of emotion. ${ }^{12}$ When emotions are shared in virtual contexts without a live video or audio stream between the participants, emotions are expressed and communicated by linguistic and symbolic means that cannot fully replace perceptually mediated processes of affective synchrony. ${ }^{13}$ Still there are shared affective experiences online insofar as the participants are mutually aware that they are feeling the same.

\subsection{Types of shared emotions}

Finally, beginning from the weakest type of shared emotion, we suggest that these emotions typically emerge when a group of individuals appraise the emotion-eliciting event convergently in relation to their overlapping private concerns, and such mechanisms as attentional deployment, emotional contagion, facial and motor mimicry, and behavioral entrainment synchronize the individuals' emotional responses, producing a

\footnotetext{
${ }^{11}$ Schmid's two examples of shared feelings with a phenomenological fusion serve as evidence for this worry. His first example are parents who grieve over the death of their beloved child. The parents share a concern for the child and its well-being in a jointly committed sense that emerges from their love for the child as parents and their reciprocal affective ties as a couple. The second example is joy at the first performance of a symphony, shared by all participants of the event, including the audience, members of the orchestra, the composer, and the stage manager. All participants share a concern about the success of the performance but in significantly different roles. The musicians have jointly committed themselves to offering an excellent performance, whereas the audience has not committed itself to anything; its role amounts to attentive listening at most. Therefore, if a successful performance elicits shared joy with a phenomenological fusion of feelings among everyone present, as Schmid suggests, the emotions of the participants are significantly dissimilar to each other in terms of the underlying concerns, unlike in the case of the grieving parents.

${ }^{12}$ For a more thorough theoretical account on the elicitation of shared emotions, see von Scheve and Ismer (2013).

${ }^{13}$ Existing studies on affective synchrony focus on face-to-face interaction, and there is a lacuna in the understanding of the kind of processes that contribute to the synchronization of individual emotions in computer-mediated, linguistic and symbolic communication insofar as synchronization occurs in these contexts. Therefore, we treat the better understood emotional sharing in face-to-face interaction as a paradigm case in our analysis.
} 
shared affective experience among individuals who are mutually aware that others are feeling the same. ${ }^{14}$ An example of this kind of shared emotion is shareholders' fear of a market meltdown. Moderately shared emotions have moderately collective concerns as the underlying ground of emotional appraisals. A shared affective experience emerges through similar mechanisms, and shared group membership reinforces the synchronization process, adding to the intensity of the shared affective experience. Moderately shared emotions are functionally and phenomenologically experienced in the role of a group member, but the group membership is normatively weak because it is maintained through a private identification or commitment. Here an example could be joy about the victory of one's favorite football team that one shares with other fans of the team. Finally, strongly shared emotions are felt as a group member in a normatively strong sense that is founded on a collective commitment to the underlying shared concern. The strong collectivity of an emotion is also reflected in the degree of synchronization of individual emotional responses and in the evaluative content of the group members' emotions. Thus the members of a winning team do not rejoice merely in winning the championship but instead in "our winning the championship" or in "our accomplishment". In this way, collective content in the sense of indexicality and mode are built into shared emotions of the strongest kind.

We will return to the typology of shared emotions in Section 6 where we will argue that stronger types of shared emotions contribute significantly to both Pacherie's outcome-based sense of agency for joint action and to our agential sense of we-agency. Before that, we discuss in detail different mechanisms that contribute to the emergence of shared affects in joint action. This discussion will show that shared affects motivate people to participate in joint action by creating a positive, rewarding experience of weagency.

\section{Mechanisms of shared affect in joint action}

In the previous section we suggested that shared emotions involve interpersonal synchrony in both cognitive and bodily processes. Accordingly, they can enhance both the predictability of others' actions and an agentive sense of weagency. In this section, we discuss several ways in which shared emotions and feelings can emerge in joint action, rendering it rewarding to the co-agents, and thereby also contributing to their sense of we-agency. Shared emotions have similar effects across different degrees of collectivity, but there are several mechanisms through which these effects become more robust when shared emotions are stronger in terms of evaluative intentionality and affective experience. First we review evidence on the affective rewards of mere behavioral synchrony (5.1), which Pacherie and Tollefsen also mention, and then complement it with the literature on collective effervescence (5.2), which they don't discuss. This affective mechanism can illustrate a way in which ritualistic interactions

\footnotetext{
${ }^{14}$ Shared emotions of this kind may not be collectively intentional as they lack a shared intentional object and an underlying shared concern. However, we would not go so far as to deny that these emotions are collective or shared in any sense. Empirical studies of shared or collective or group emotions generally do not distinguish between these importantly dissimilar types of shared emotions even if their social consequences can differ significantly, as we argue in Salmela and Nagatsu 2016.
} 
facilitate social cohesion by providing affective rewards, but it leaves unexplained why stronger forms of shared emotions rather than mere synchrony are more powerful in this regard. So we employ Adam Smith's classic theory of fellow-feelings to explain this (5.3). Lastly we extend our cases to social exchanges in general, and argue that the same affective mechanisms are at play in instrumental interactions (5.4).

\subsection{Affective rewards of behavioral synchrony}

An association between synchronised behavior and positive interpersonal affect has been established in several studies. These affective rewards including feelings of solidarity, rapport, affiliation, interpersonal liking, as well as prosocial and cooperative motivation, are associated with different types of synchrony, such as synchronized motor representations (Rizzolatti and Craighero 2004), body postures and gaze patterns (Shockley et al. 2009), speech patterns (Fowler et al. 2008), facial expressions (Chartrand and Bargh 1999), or heart rate (Vikhoff et al. 2013) of the interacting agents. Importantly, synchrony yields affective rewards even when it is accidental rather than purposefully achieved by the participants, e.g., when individuals walk, tap fingers, rock chairs, and so on, or perceive figures or sounds (e.g. Hove and Risen 2009; Miles et al. 2009). In these cases, there is little opportunity for feedback and little history of social interaction, or reason to suppose the presence of shared intentionality in acting. Nevertheless, individuals who engaged in synchronous behavior reported greater feelings of interpersonal connectedness, rapport, and affiliation, and they sometimes cooperated more in social dilemma situations than people in asynchronous conditions (Wiltermuth and Heath 2009). This suggests that behavioral synchrony constitutes a basic building block for our daily interactions with others, and the inherently rewarding aspect of such behaviors explains why we are prima facie motivated to participate in joint actions that involve aspects of synchrony (Godman 2013; Godman et al. 2014).

The fact that synchronous behaviors are regular part of joint action, as Pacherie (2014) and Tollefsen (2014) have observed, implies that this mechanism of shared affect also operates in most instances of joint action. Of course, the affective rewards of synchrony may not suffice to render the overall affective quality of a joint action hedonically positive, as when we carry a heavy sofa together, for example. But if individuals experience even contingent behavioral synchrony as rewarding in its own right, we should expect them to purposefully engage in forms of social interaction in which synchrony and the adjacent rewards are produced. This seems to happen in ritualistic behaviors such as plays, games, singing, dancing, worship, and other ceremonies. We now turn to the affective experience in these rituals.

\subsection{Collective effervescence}

The Durkheimian tradition of sociology has analyzed the emergence of shared emotions in ritualistic social interaction. These theorists suggest that the function of all social interaction, whether or not we are aware of it, is to produce affective rewards for the participants and to reinforce social cohesion in the 
group (e.g. Durkheim [1912] 2001; Collins 2004, 2014; Knottnerus 2010; Summers-Effler 2007). This ultimately serves to increase the adaptiveness of the community (Collins 2004). At the proximate level, we seek affective boost from interactions that we have experienced as rewarding and avoid emotionally draining interactions. Indeed, for ritual theorists, the fundamental drive to maximize our emotional energy is "behind individual behavior, group activity, culture, and networks" (Summers-Effler 2007, 139).

Durkheim is the locus classicus of the ritualistic tradition with his notion of collective effervescence (effervescence collective) though he did not develop an elaborate theory of collective emotions. His analysis of the ritualistic emergence of collective emotions in the gatherings of people with common beliefs and convictions has offered the foundation for later sociological accounts, such as Randall Collins' theory of the emergence and reproduction of collective emotions in the context of interaction rituals that we discuss below.

Ritual ingredients include a group of people who are physically assembled in the same place and separated from those who are excluded from the ritual. The group members focus their attention on some common object or activity, and by communicating this focus to each other become mutually aware of their shared focus of attention. Finally, the group members share a common mood or emotion. These initiating affects spread and intensify in the group's interaction rituals, such as chants, songs, dances, or games, through emotional contagion and rhythmic synchronization of bodily responses as well as through the group members' reflexive awareness of their shared experience. Collins characterizes the result as collective effervescence, i.e., heightened intersubjectivity in which "[ $\mathrm{t}]$ he key process is participants' mutual entrainment of emotion and attention, producing a shared emotion/cognitive experience" (Collins 2004, 48). A successful interaction ritual produces emotional energy - confidence, enthusiasm, and good self-feelings - for the participants; collective symbols - emblems, signs, slogans, buzzwords, ideas, or other representations - also infused with emotional energy; feelings of solidarity; and standards of morality: respect for the group and its symbols and anger at violations against them.

From our perspective, the main contribution of ritualistic theories is their detailed description of how the emotional quality of ritualistic activities builds up from the elements of engagement in joint activity, such as the separation of the participants from the rest, their shared focus of attention, and an initial common mood or emotion. The emergence of collective effervescence is a dynamic process which proceeds from the mutually reinforcing interplay of these ritual ingredients.

Although Pacherie does not refer to the literature on collective effervescence, it enriches and benefits her discussion on the sense of we-agency in joint action. First, at the height of collective effervescence, the participants of a ritual may also experience the kind of oneness, or a loss of boundary between self- and other-agency, that Pacherie highlights as a sense of pure we-agency. Second, affective rewards from behavioral synchrony and alignment that Pacherie mentions may constitute one source of the initial shared affective state that spreads and intensifies in the course of an interaction ritual. We suggest that another source of shared affects in rituals are internal goals and standards of excellence of rituals, such as staying in the same rhythm when we are dancing or singing together, doing some difficult part of our joint performance, and completing the performance rather than interrupting it. Shared emotions may emerge as 
rational responses to jointly achieving or failing to meet those internal norms of rituals. Such emotions include excitement before and during the performance of a ritual; joy when it succeeds; fear when its successful performance is threatened; disappointment at its failure; anger at those disturbing the ritual or violating its rules, and so on (Parkinson et al. 2005; Helm 2008; Salmela 2012).

This motivation for joint activities internal to rituals and the rewards from them are the key to unpacking what the ritual theories mean by "emotional energy" that motivates people to return to those activities, either with the same interactors, or with other masters of the same activities as is the case with singing and dancing, for instance. But we still haven't explained why successful rituals create feelings of solidarity and interpersonal liking. What is it in sharing emotions with others that has these effects? We argue that Adam Smith's classic theory of fellow-feelings addresses this question.

\subsection{Fellow-feelings and the pleasure in corresponding sentiments}

Smith, in his classic The Theory of Moral Sentiments (1759), argues that our prosociality and tendency to do things together with others rather than alone can be explained by a reward produced in a two-stage psychological mechanism.

Fellow-feeling is a form of empathy that allows us to feel, in a weaker degree, what another person feels through an imaginative placing of ourselves into his or her situation. As lively consciousness of another person's affective state, fellow-feeling produces correspondence of sentiments between the empathizing and the empathized subject. When the subjects become aware of the correspondence of sentiments, this realization gives them an additional source of pleasure. Smith claims that this awareness is rewarding regardless of whether the given sentiment is pleasurable or painful, and that the pleasure from correspondence overweighs the painful sentiment such that people seek such correspondence whenever possible. In Smith's words, the awareness of correspondence in sentiments "enlivens joy and alleviates grief." (Smith [1759] 2002, 18).

Robert Sugden (2002) claims that Smith is best interpreted as arguing for a general hypothesis that any correspondence of sentiments, whether caused by a fellow-feeling or some other mechanism, is a source of pleasure, and the lack thereof a source of pain. From our perspective, another important way in which people come to have corresponding sentiments is by sharing emotions grounded on a shared concern. In sum, the Smith-Sugden hypothesis states that this reward from the correspondence of sentiments, whether it comes from fellow-feelings or shared emotions, is primarily responsible for individuals' tendency to try to align their sentiments with those of others. Accordingly, the feelings of solidarity and interpersonal liking that ritualists highlight are subjective manifestations of this specific reward system.

The Smith-Sugden hypothesis explains some phenomena that ritualistic theorists of social interaction have identified, but without specifying their psychological mechanisms. Collins argues that the initial common affects of individuals can be either positive or negative but the resulting collective emotional experience nevertheless has a positive quality or side to it. For instance, in funerals the ritual allows the bereaved family members and friends of the deceased to express their grief to each other and become consoled by the shared experience. The same mechanism operates in positive 
emotions where awareness of shared experience amplifies the positive quality of the experience. Experience tells us that watching a game of our favorite team is more exciting and fun when we do it together with fellow fans of the team, either at the stadium or at home via TV, than watching the game alone. Pleasures of awareness of "feeling the same" emerge when individuals become aware of their shared sentiments, and the anticipation of those inherently pleasant feelings reinforces future interactions in which such sentiments are likely to be experienced.

The Smith-Sugden hypothesis can also account for the difference between rewards from joint intentional actions and those from mere behavioral synchrony discussed in 5.1. The latter have been reported in studies in which synchrony was accidental rather than purposefully achieved by the participants and there is little opportunity for the participants to be aware of the corresponding sentiments in others. The pleasure from shared feelings and emotions in contrast crucially depends on such awareness. Evidence from these synchrony studies suggests that convergent positive feelings brought about by behavioral synchrony may function as coordination smoothers. If this is the case, shared emotions experienced in joint intentional activities such as singing and dancing, or preparing dinner together are likely to be even more efficient and reliable in achieving a joint goal, since those emotions of which the participants are mutually aware provide them both pleasure in correspondence and important feedback on their progress in the joint task. Indeed, many synchrony studies have been conducted in the context of joint intentional activities (e.g. Kirschner and Tomasello 2010; Reddish et al. 2013). Here mere synchrony does not explain the emotional effects of joint action because shared emotions based on shared goals of the action and its actual performance also contribute to the participants' reported positive emotions, strengthening the rewards from converging sentiments.

\subsection{Shared affects in social exchange}

Ritualistic joint actions have no proximate purpose beyond the activity. Therefore, it is plausible that we engage in those activities for their intrinsic affective rewards. However, we also do things together with others for instrumental reasons, in order to reach our individual goals by means of joint action. In this subsection, we show that affective rewards from sharing emotions are relevant in those instrumental joint actions as well.

Instrumental joint actions serve the self-interest of the participants by yielding rewards or outcomes that the participants value individually rather than collectively. When this kind of interaction is repeated, we can talk about social exchange. In general, a social exchange takes two or more people to accomplish it; the participants have to coordinate with one another in order to succeed in the task; and they experience costs if they fail in the task (Lawler et al. 2009, 56). Many economic and social interactions have these features, which game theorists model as problems of coordination and cooperation, with and without conflict.

Edward Lawler, Shane Thye, and Jeongkoo Yoon have argued in a series of empirical and theoretical contributions (e.g. 2008, 2009, 2014) that social exchanges that begin with instrumental motivations are capable of giving rise to strong affective person-to-person and person-to-social unit ties that transform the motivational structure of those exchanges. The idea is that emotions and feelings emerge as by-products of instrumental social exchange but once generated, they transform instrumental transactional ties into expressive relational ties where affiliation with the relevant exchange 
partners and unit comes to have an intrinsic value. The theory breaks into two complementary horns, relational cohesion theory and affect theory of social exchange, both of which highlight the role of shared affects arising from social exchange.

The relational cohesion theory focuses on the dependence or interdependence of actors. The theory suggests that when there is equal power relation and high interdependence between the actors, repeated exchanges in these conditions produce positive emotions, which in turn produce perceptions of relational cohesion, which further increase exchange frequency and commitment behaviors such as staying in the relationship in spite of having better alternatives, and cooperating in a social dilemma situation (see also Michael and Pacherie 2015). A voluntary choice of exchange partners amplifies this endogenous process in comparison to an involuntary one. Importantly, this process of from-exchange-to-emotion-to-cohesion has been reported in experiments where anonymous subjects negotiate agreements across several episodes via computers without ever seeing each other or the other actor's payoffs (Lawler et al. 2008). Although these standard conditions of social psychological research militate against the endogenous process, evidence supports the predictions of the theory.

The affect theory of social exchange introduces the notion of social unit attribution as a link between individual emotions and person-to-group affective ties. Thus Lawler and others suggest that successful social exchange gives rise to positive feelings and emotions, such as excitement, pleasure, gratitude, and pride, which are attributed to or associated with the relevant relational units or social groups. Attributions of emotions to social units involve attachment when individual emotions from social exchange are positive, and detachment when those emotions are negative. These attributions are strongest in joint tasks with high interdependence and shared responsibility of the actors. The greater the non-separability of individuals' impact on the success or failure in a joint task, the greater the perception of shared responsibility for success or failure in the task, and, consequently, the inclination of agents to attribute the resulting emotions to the relevant social unit. When social unit attributions are strong, successful exchanges result in positive emotions for everyone involved: pride in self and gratitude toward others. Mutually felt positive emotions also increase interpersonal trust and solidarity, understood as "the strength and durability of person-to-group and person-to-person relations" (Lawler 2001, 329).

In a recent theoretical contribution, Lawler et al. (2014) suggest that shared emotions reinforce the processes of relational cohesion and social unit attribution. The emergence of shared emotions requires that the participants of a joint task become aware of their sharing the same emotion. Our discussion in the previous subsection (5.3) indicates that shared emotions strengthen the processes of relational cohesion and social unit attribution through the pleasures from corresponding sentiments that emerge when the participants of a joint task become aware of feeling the same. Since joint actions that figure in social exchange are typically temporally extended with agents who form a longer-term collective, these mechanisms of shared affect are likely to underpin the processes that Lawler and his colleagues articulate in their theory of social exchange. 


\section{Shared emotions and the phenomenology of joint action}

Finally, it is time to bring the preceding discussion on the mechanisms of shared affect in joint action to bear on the phenomenology of joint action, and on the sense of we-agency in particular. In Section 5 we showed how our account of shared emotions and the sense of we-agency accommodates the various forms of affective experience in joint action. In particular, we have seen that shared emotions are noncontingent concomitants and consequences of most joint actions, even in instrumentally motivated social exchanges. Shared emotions are capable of rendering joint actions rewarding in their own right to the participants. This is already an important contribution to the phenomenology of joint action as it implies one answer to the question, How does it feel to act together? Simply put, it feels good. However, shared emotions contribute to the more specific phenomenology of we-agency in many respects as well. In this penultimate section, we discuss these respects to show how our account coheres better with Pacherie's sense of agency for joint outcomes than her own "oneness" account of we-agency.

Remember Pacherie's structural conditions that favor the sense of agency for joint outcomes: "participation in small-scale, egalitarian actions, with little specialization of roles and a stable group of co-agents, is likely to yield a stronger sense of agency than first-time participation in a large-scale, hierarchical joint action with highly differentiated roles" (Pacherie 2014, 35). We propose that these conditions also contribute to the emergence of shared emotions and feelings that enhance both the predictability of other agents' actions that Pacherie highlights in her outcome-based sense of agency for joint action, and the agentive sense of we-agency that coexists with a strong sense of self-agency. We put forward the latter as the core sense of we-agency.

The structural conditions of the sense of agency for joint outcomes support the emergence of shared emotions in many ways. First, the small scale of joint action typically brings along a shared physical environment in which the co-agents can perceive each other's actions during their joint action. Together with near-identical or interchangeable roles, the small scale of joint action contributes to nonconscious behavioral synchrony and motor simulation which give rise to positive feelings in the sense of increased affiliation and positive relationships, as Pacherie remarks. We add that these affective rewards are typically mediated and reinforced by the co-agents' mutual awareness that the others are feeling the same. Indeed, the small scale of joint action such as singing or dancing together allows for and supports such awareness. Ritualistic joint actions of this kind are also paradigmatic examples of collective effervescence in which shared emotions intensify and spread among the co-agents through extensive behavioral synchrony and entrainment. Finally, the stability of the co-agents and their shared social identity are important for emotional mimicry and contagion as we mimic the facial, vocal, and postural expressions of emotion more with those with whom we share group membership than with out-group members or, even less so, our enemies (Hess et al. 2014). Here we can surmise that group membership founded on a collective commitment associates with more robust affective synchrony than group membership based on merely private affiliation. Emotional alignment in turn contributes to the predictability of other agents' actions. 
Michael (2011) points out that emotional alignment functions as a coordination smoother in joint action in several ways. First, it increases people's motivation to act jointly with each other as they find others in similar affective states warmer and more cooperative as pointed out in 5.1. Besides motivational effects, emotional convergence also contributes to cognitive and bodily alignment as "two or more people with congruent emotions will tend to be influenced in the same ways and will therefore tend to converge, or align, with each other. This would make it easier to predict each other's actions and to coordinate movements" (Michael 2011, 366). Emotional alignment facilitates the coagents' ability to make accurate joint predictions through its effects on attention and memory as well. "If two people are emotionally aligned, it will increase the likelihood of noticing the same objects in the context of a joint action. This would facilitate prediction of each other's behavior, since knowing what people are attending to provides clues about the actions they are likely to initiate" (ibid., 367).

In fact, emotional alignment does not merely increase the likelihood of joint attention. On our account of shared emotions, joint attention to the shared intentional object of emotion is a central aspect of both moderately and strongly shared emotions. The synchronizing and coordinating effects of these emotions are accordingly more robust than those of weakly shared emotions whose intentional objects are individual tokens of the same type as in the case of shareholders' fear for their investments.

Emotional alignment also contributes to the agentive sense of we-agency. Here the egalitarian context of joint action is perhaps more important than the other structural factors that facilitate the emergence of shared emotions. Equal participation in the planning and execution of a joint action does not of course directly give rise to shared emotions. However, it contributes to the co-agents' private or collective commitment to their shared goal, whether or not there is a distinct act of joint or collective commitment as some philosophical theorists of joint action maintain (Gilbert 2003, 2014; Tuomela 2007, 2013). Through their contribution and commitment to the shared goal, the goal becomes the co-agents' shared concern that provides them both motivating and justifying reasons to think, want, act, and feel in ways that are in accordance with their shared concern, as we pointed above in the discussion on strongly shared emotions (Section 4). Importantly, this is not merely a normative claim as it draws on empirical findings (Parkinson et al. 2005). In other words, shared emotions are not merely contingent responses to events relating to joint goals but part of a projectible pattern of rationality in the co-agents' responsiveness to the world, as Bennett Helm (2008) emphasizes in his account of "plural agency".

Our proposal is therefore that the agentive sense of we-agency of "sharing the same fate" or "being in the same boat" (Tuomela 2007) is experienced centrally through shared emotions that accompany joint action and rationally relate to its joint goals (see also Salmela and Nagatsu 2016). These emotions express the co-agents' commitment to the joint goal and its mutuality which highlights the agents' interdependence in the task. Shared emotions inform the co-agents about their progress toward the joint goal and about their possible setbacks in its pursuit; not merely factually but also evaluatively, in terms of what those progresses or setbacks mean to the participants. These shared emotions allow the co-agents to have a strong sense of we-agency even when 
they have relatively specific roles in their joint action, and therefore also a robust sense of self-agency, as in the case of sports teams. This sense of weagency manifests in the emotional content such that the co-agents feel joy and pride "that we did it" if they reach their joint goal; sadness or disappointment "that we failed" if they don't; anger at those who "harmed or wronged $u s$ " by preventing them from reaching their joint goal; and so on. These emotions, especially positive ones, also motivate the co-agents to engage in joint action. In sum, these shared affects constitute a central part of the togetherness and interdependence that we experience in joint action.

\section{Conclusion}

In this paper, we have developed an account of the phenomenology of joint action building on Pacherie's. Our position is both complementary and critical to hers. First we complemented Pacherie's account of how the first sense of agency for joint action, which is outcome-based, arises, by explicating a set of affective mechanisms through which this sense of agency for joint action is enhanced. We however turned this account to criticize Pacherie's understanding of the second sense of agency for joint action, which she assumes to be incompatible or essentially in tension with self-agency. We instead argued that shared emotions that are experienced in the course and consequence of joint action contribute centrally to an agentive sense of we-agency that has no tradeoff with the sense of self-agency.

Our account of the phenomenology of joint action, like Pacherie's, draws on both philosophical and empirical studies on joint action. Correspondingly, our main contributions are both philosophical and empirical. On the empirical front, we draw on much the same literature as Pacherie, but we pay distinct attention to the affective and motivational mechanisms and to how these contribute to the "feel" of joint action. On the philosophical front, we apply this empirically grounded understanding to move beyond simply applying the model of individual agency to the model of agency for joint action, and put forward the model of agency for joint action that highlights shared emotions as a theoretical framework to understand the phenomenology of joint action.

Acknowledgments We thank Elisabeth Pacherie, John Michael, Hans Bernhard Schmid, Michael Schmitz, and two anonymous reviewers of this journal as well as the audience at the Philosophy of Science seminar, University of Helsinki, Sep 21, 2015 for their insightful and constructive comments to earlier versions of this paper.

\section{References}

Bourgois, P., \& Hess, U. (2008). The impact of social context on mimicry. Biological Psychology, 77, 343-352. Brady, M. (2011). Emotions, perceptions, and reasons. In C. Bagnoli (Ed.), Morality and the emotions (pp. 135-149). Oxford: Oxford University Press.

Bratman, M. E. (2014). Shared agency. A planning theory of acting together. New York: Oxford.

Chartrand, T. L., \& Bargh, J. A. (1999). The chameleon effect: the perception-behavior link and social interaction. Journal of Personality and Social Psychology, 76, 893-910.

Collins, R. (2004). Interaction ritual chains. Princeton and Oxford: Princeton University Press. 
Collins, R. (2014). Interaction ritual chains and collective effervescence. In C. von Scheve \& M. Salmela (Eds.), Collective emotions (pp. 299-311). Oxford: Oxford University Press.

D’Arms, J., \& Jacobson, D. (2000). Sentiment and value. Ethics, 110, 722-748.

Decety, J., \& Meyer, M. (2008). From emotion resonance to empathic understanding: a social developmental neuroscience account. Development and Psychopathology, 20, 1053-1080.

Durkheim, E. (2001[1912]). The elementary forms of religious life. A new translation by C. Cosman. Abridged with an introduction and notes by M.S. Cladis. Oxford: Oxford University Press.

Fowler, C. A., Richardson, M. J., Kerry, L. M., \& Shockley, K. D. (2008). Language use, coordination, and the emergence of cooperative action. In A. Fuchs \& V. Jirsa (Eds.), Coordination: Neural, behavioral and social dynamics (pp. 261-279). New York: Springer.

Gilbert, M. (2002). Collective guilt and collective guilt feelings. The Journal of Ethics, 6, 115-143.

Gilbert, M. (2003). The structure of the social atom: Joint commitment as the foundation of human social behavior. In F. Schmitt (Ed.), Socializing metaphysics (pp. 39-64). Lanham: Rowman \& Littlefield.

Gilbert, M. (2014). Joint commitment: How we make the social world. New York: Oxford University Press.

Godman, M. (2013). Why we do things together: the social motivation for joint action. Philosophical Psychology, 26, 588-603.

Godman, M., Nagatsu, M., \& Salmela, M. (2014). The social motivation hypothesis of prosocial behavior. Philosophy of the Social Sciences, 44, 563-587.

Greenspan, P. S. (1988). Emotions and reasons. An inquiry into emotional justification. New York: Routledge.

Gregg, M., \& Seigworth, G. J. (Eds.). (2010). The affect theory reader. Durham: Duke University Press.

Halperin, E. (2014). Collective emotions and emotion regulation in intractable conflicts. In C. von Scheve \& M. Salmela (Eds.), Collective emotions (pp. 281-295). Oxford: Oxford University Press.

Hatfield, E., Cacioppo, J., \& Rapson, R. (1994). Emotional contagion. New York: Cambridge University Press.

Helm, B. (2008). Plural agents. Nô̂s, 42, 17-49.

Hess, U., Houde, S., \& Fischer, A. (2014). Do we mimic what we see or what we know? In C. von Scheve \& M. Salmela (Eds.), Collective emotions (pp. 94-107). Oxford: Oxford University Press.

Hove, M. J., \& Risen, J. L. (2009). It's all in the timing: interpersonal synchrony increases affiliation. Social Cognition, 27, 949-960.

Huebner, B. (2011). Genuinely collective emotions. European Journal for Philosophy of Science, 1, 89-118.

Kirschner, S., \& Tomasello, M. (2010). Joint music making promotes prosocial behavior in 4-year-old children. Evolution and Human Behavior, 31, 354-364.

Knottnerus, J.D. (2010). Collective events, rituals, and emotions. In S.R. Thye \& E.J. Lawler (Eds.), Advances in group processes (vol. 27, pp. 39-62). Bingley: Emerald Publishing.

Lakin, J. L., Jefferis, V. E., Cheng, C. M., \& Chartrand, T. L. (2003). The chameleon effect as social glue: evidence for the evolutionary significance of nonconscious mimicry. Journal of Nonverbal Behavior, 27, $145-162$.

Lambie, J. A., \& Marcel, A. J. (2002). Consciousness and the varieties of emotion experience: a theoretical framework. Psychological Review, 109, 219-259.

Lawler, E. J. (2001). An affect theory of social exchange. American Journal of Sociology, 107, 321-352.

Lawler, E. J., Thye, S. R., \& Yoon, J. (2008). Social exchange and micro social order. American Sociological Review, 73, 519-542.

Lawler, E. J., Thye, S. R., \& Yoon, J. (2009). Social commitments in a depersonalized world. New York: Russell Sage.

Lawler, E. J., Thye, S. R., \& Yoon, J. (2014). The emergence of collective emotions in social exchange. In C. von Scheve \& M. Salmela (Eds.), Collective emotions (pp. 189-203). Oxford: Oxford University Press.

Michael, J. (2011). Shared emotion and joint action. Review of Philosophy and Psychology, 2, 355-373.

Michael, J., \& Pacherie, E. (2015). On commitments and other uncertainty reduction tools in joint action. Journal of Social Ontology, 1(1), 89-120.

Miles, L. K., Nind, L. K., \& Macrae, N. (2009). The rhythm of rapport. Interpersonal coordination and social perception. Journal of Experimental Social Psychology, 45, 585-589.

Pacherie, E. (2012). The phenomenology of joint action: Self-agency vs. joint-agency. In A. Seemann (Ed.), Joint Attention: New developments (pp. 343-389). Cambridge: MIT Press.

Pacherie, E. (2014). How does it feel to act together? Phenomenology and the Cognitive Sciences, 13, $25-46$.

Parkinson, B., Fischer, A., \& Manstead, A. (2005). Emotions in social relations. New York: Psychology Press.

Reddish, P., Fischer, R., \& Bulbulia, J. (2013). Let's dance together: synchrony, shared intentionality, and cooperation. PLoS ONE, 8(8), e71182. doi:10.1371/journal.pone.0071182.

Rimé, B. (2007). Interpersonal emotion regulation. In J. J. Gross (Ed.), Handbook of emotion regulation (pp. 466-485). New York: Guilford. 
Rizzolatti, G., \& Craighero, L. (2004). The mirror-neuron system. Annual Review of Neuroscience, 27, 169-192.

Roberts, R. (2003). Emotions. Cambridge: Cambridge University Press.

Salmela, M. (2012). Shared emotions. Philosophical Explorations, 15, 33-46.

Salmela, M. (2013). The functions of collective emotions in social groups. In: H.B. Schmid and A. Konzelmann Ziv (Eds.), Institutions, emotions, and group agents. Springer Studies in the Philosophy of Sociality (vol. 2, pp. 159-176). Berlin: Springer.

Salmela, M., \& Nagatsu, M. (2016). Collective emotions and joint action: beyond received and minimalist approaches. Journal of Social Ontology, 2, 33-57.

Schmid, H.B. (2009). Plural action. Essays in philosophy and social science. Contributions to Phenomenology, vol. 58. Berlin: Springer.

Shockley, K., Richardson, D. C., \& Dale, R. (2009). Conversation and coordinative structures. Topics in Cognitive Science, 1, 305-319.

Smith, A. (2002 [1759]). The theory of moral sentiments. Cambridge: Cambridge University Press.

Sugden, R. (2002). Beyond sympathy and empathy: Adam Smith's concept of fellow-feeling. Economics and Philosophy, 18, 63-87.

Summers-Effler, E. (2007). Ritual theory. In J. E. Stets \& J. H. Turner (Eds.), Handbook of the sociology of emotions (pp. 135-154). New York: Springer.

Tollefsen, D. (2014). A dynamic theory of shared intention and the phenomenology of joint action. In S. R. Chant, F. Hindriks, \& G. Preyer (Eds.), From individual to collective intentionality. New essays (pp. 1333). Oxford: Oxford University Press.

Tuomela, R. (2007). The philosophy of sociality. New York: Oxford University Press.

Tuomela, R. (2013). Social ontology. Collective intentionality and group agency. New York: Oxford University Press.

van Baaren, R. B., Holland, R. W., Kawakami, K., \& van Knippenberg, A. (2004). Mimicry and prosocial behavior. Psychological Science, 15, 71-74.

Vikhoff, B., Malmgren, H., Åström, R., Nyberg, G., Ekström, S.-R., Engwall, M., Snygg, J., Nilsson, M., \& Jörnsten, R. (2013). Music structure determines heart rate variability of singers. Frontiers in Psychology, 4(334), 1-16.

von Scheve, C., \& Ismer, S. (2013). Towards a theory of collective emotions. Emotion Review, 5, 406-413. Wiltermuth, S. S., \& Heath, C. (2009). Synchrony and cooperation. Psychological Science, 20, 1-5.

Zahavi, D. (2015). You, me and we-the sharing of emotional experiences. Journal of Consciousness Studies, $22,84-101$. 